\title{
Physicochemical Properties and Biological Activities of Silver Carp Scale Peptide and Its Nanofiltration Fractions
}

\author{
Xiao-yan Zu ${ }^{1}$, Ya-jing Zhao ${ }^{1,2}$, Shi-ming $\mathrm{Fu}^{1}$, Tao $\mathrm{Liao}^{1}$, Hai-lan $\mathrm{Li}^{1 *}$ and \\ Guang-quan Xiong ${ }^{1 *}$
}

1 Institute of Agricultural Products Processing and Nuclear Agricultural Technology, Hubei Academy of Agricultural Sciences, Wuhan, China, ${ }^{2}$ College of Petrochemical, Lanzhou University of Technology, Lanzhou, China

OPEN ACCESS

Edited by:

Shuai Chen,

Wuhan University, China

Reviewed by:

Quancai Sun,

Jiangsu University, China

Tao Feng,

Shanghai Institute of

Technology, China

Ru Liu,

Huazhong Agricultural

University, China

*Correspondence:

Hai-lan Li

hl.li@hotmail.com

Guang-quan Xiong

xiongguangquan@163.com

$$
\begin{array}{r}
\text { Specialty section: } \\
\text { This article was submitted to } \\
\text { Food Chemistry, } \\
\text { a section of the journal } \\
\text { Frontiers in Nutrition }
\end{array}
$$

Received: 10 November 2021 Accepted: 09 December 2021

Published: 04 January 2022

Citation:

Zu X-Y, Zhao Y-J, Fu S-M, Liao T,

Li H-L and Xiong G-Q (2022)

Physicochemical Properties and Biological Activities of Silver Carp

Scale Peptide and Its Nanofiltration

Fractions. Front. Nutr. 8:812443.

doi: 10.3389/fnut.2021.812443
To explore the physicochemical properties and biological functions of silver carp scale peptide (SCSP), its molecular-weight fractions SCSP-I, II, and III obtained by nanofiltration were assessed for their solubility, emulsibility, free radical scavenging ability, effect on the proliferation of mouse B16 cells. The results showed that the solubility of each fraction of SCSP was higher than 90\%, SCSP-II and III were higher than 95\%. The antioxidant powers on $\bullet \mathrm{OH}, \mathrm{O}_{2}^{-} \bullet$ and $\mathrm{Fe}^{3+}$ were ranked as SCSP-III $>$ SCSP-II > SCSP-I > SCSP. All fractions of SCSP had no toxic or side effects in mouse B16 melanoma cells experiments in vitro. At a concentration of $0.01 \mathrm{mg} / \mathrm{mL}$, the tyrosinase activity of B16 cells in the SCSP-II fraction was significantly lower than that of the $\alpha$-arbutin $(P<0.05)$, at $65.37 \%$. The molecular weight distribution of SCSP was 399-1404 Dalton and 13 peptide sequences were detected. Among them, SCSP-II contained many hydrophobic amino acids, and SCSP-III stood out for combining arginine with hydrophobic amino acids. This may be the reason why the low molecular-weight SCSPs show the strong antioxidant activity and strong tyrosinase inhibition. The work provides a data base for the development of SCSP and increases the possibility of its application.

Keywords: silver carp scale peptide, physicochemical properties, free radical scavenging, tyrosinase inhibition, amino acid sequence

\section{INTRODUCTION}

Silver carp (Hypophthalmichthys molitrix) is widely distributed in lakes and rivers across Asia. A fast-growing fish, it has high feed efficiency and high nutritional value, so it is one of the four major farmed freshwater fishes in China. In 2020, the aquaculture production of silver carp reached 3.81 million tons, second only to grass carp (Ministry of Agriculture Fishery Administration., 2021). During the processing of silver carp, many by-products are produced, including fish heads, bones, skins, and internal organs. Their weight accounts for approximately $50-70 \%$ of the total body weight of the fish, of which fish scales account for approximately 5\% (1). For a long time, fish scales have been considered of low value, so the rate of fish scale utilization and processing has been low, resulting in the serious waste of biological resources. 
The high-quality collagen that is enriched in fish scales can undergo the disintegration of molecular chains via hydrolysis, forming peptide mixtures between proteins and amino acids (2). Fish scale peptide is characterized by high solubility, good thermal stability, and easy absorption (3). And it can have multiple biological functions such as binding to mineral ions (4), inhibiting aging and antioxidation (5). Addition, according to Ma's conclusion that short peptides containing 2-10 amino acids have greater antioxidant potential and biological activity than their native proteins or peptides (6). The composition and proportion of hydrophobic amino acids (e.g., Pro, Ala, Val, Phe, Leu, Ile) in the sequence are also related to the antioxidant activity of polypeptides (7), the presence of hydrophobic amino acid residues can enhance the antioxidant capability of peptides, and the higher their content, the stronger the antioxidant activity (8).

Excellent biocompatibility and low immunogenicity enable the fish scale peptides to be used in biomedical fields, such as wound healing and medical dressings. Due to its strong antioxidant, moisturizing, and whitening properties, fish scale peptide has been approved for uses in cosmetics, health foods, and other products $(9,10)$. At present, the overuse of popular skin-whitening agents on the market, such as arbutin and hydroquinone, can cause permanent white patches on the skin (11). Therefore, it is imperative to find a safe and effective natural inhibitor of melanin synthesis.

In this paper, the physicochemical properties of silver carp scale peptide (SCSP) and its three molecular-weight fractions were studied. The amino acid sequences and molecular weights of the corresponding peptides were identified by mass spectrometry. Free radical scavenging assays, in vitro cell experiments, and a tyrosinase inhibition assay were carried out to verify their antioxidant and whitening effects. This study is expected to provide technical support for the development of SCSP as a consumer product.

\section{MATERIALS AND METHODS}

\section{Materials}

Silver carp scales were purchased from Liangzihu Aquatic Products Processing Co., Ltd. (Wuhan, China). Soybean oil (food grade) was from the COFCO Fulinmen Food Marketing Co., Ltd. (Wuhan, China). Alkaline protease (liquid, 2,400,000 $\mathrm{U} / \mathrm{mL}$ ) was from Genencor (China) Bioengineering Co., Ltd. 2, 2Diphenyl-1-picrylhydrazyl (DPPH) was from Sigma Corporation (USA). B16-F1 mouse melanoma cells were from the China Center for Type Culture Collection (CCTCC, Hubei, Wuhan). 3-(4, 5-Dimethylthiazol-2-yl)-2, 5-diphenyltetrazolium bromide (MTT) was purchased from BioFroxx (Germany). TrypsinEDTA $(0.25 \%)$, fetal bovine serum, and penicillin-streptomycin were from GIBCO (New York, USA). Chromatographically pure acetonitrile was from Thermo Fisher Scientific Co., Ltd. (Shanghai, China). All other reagents used in the experiment were of analytically pure grade and were from Sinopharm Chemical Reagent Co., Ltd. (Shanghai, China).

\section{Technical Route}

In this study, decalcified silver carp scales were hydrolyzed with alkaline protease to obtain an enzymatic hydrolysate. After removing the enzymes, the enzymatic hydrolysate was separated by nanofiltration to prepare different molecular-weight fractions of SCSP. The physicochemical properties and biological activities of SCSP and its three molecular-weight fractions were studied. The technical flow chart is shown in Figure 1.

\section{Preparation of SCSP and Its Nanofiltration Fractions}

The decalcified silver carp scales were cleaned with deionized water to remove impurities and mixed with deionized water at a ratio of 1:50 (w/v), and $0.01 \mathrm{M}$ sodium hydroxide $(\mathrm{NaOH})$ was used to adjust the solution $\mathrm{pH}$ to 8.0. Then alkaline protease was added, and the mixture was mixed evenly and placed at $50^{\circ} \mathrm{C}$ to undergo enzymatic hydrolysis until all the solid scales had disappeared. The enzymatic hydrolysate was inactivated at $100^{\circ} \mathrm{C}$ for $10-15 \mathrm{~min}$ and then centrifuged at 5,000 rpm for $20 \mathrm{~min}$ to remove the impurities and enzymes to obtain the SCSP.

The SCSP was filtrated and separated with a nanofiltration membrane (S-UF3, Shanghai Langji membrane separation equipment Engineering Co., Ltd., China) with a molecular weight cut-off of 5,000 Dalton (Da), and the filtrate continued to be separated by a nanofiltration membrane with a molecular weight cut-off of 3,000 Da. The substances retained by the 5,000-Da nanofiltration membrane were the SCSP-I fraction, the substances retained by the $3000-\mathrm{Da}$ nanofiltration membrane were the SCSP-II fraction, and the filtrate that passed through the 3,000-Da nanofiltration membrane was the SCSP-III fraction. The SCSP sample before nanofiltration and different molecularweight fractions were freeze-dried for later use.

\section{Determination of Solubility}

The method of Adler-Nissen et al. (12) was used as a reference for the determination of collagen peptide solubility, with slight modifications. In $50 \mathrm{~mL}$ of distilled water, $5 \mathrm{mg}$ of the freeze-dried SCSP, SCSP-I, SCSP-II, and SCSP-III samples were dissolved, and the $\mathrm{pH}$ values were, respectively, adjusted to $3.0,4.0,5.0,6.0$, $7.08 .0,9.0$, and 10.0 with $6.0 \mathrm{M} \mathrm{HCl}$ or $6.0 \mathrm{M} \mathrm{NaOH}$ solution, followed by centrifugation at $4,000 \mathrm{rpm}$ for $20 \mathrm{~min}$. In $1 \mathrm{~mL}$ of the supernatant, the biuret method was used to determine the polypeptide contents. The solubility of SCSP and its fractions was calculated according to Equation (1), and the result is expressed as the nitrogen solubility index (NSI):

$$
\mathrm{NSI}(\%)=\frac{\mathrm{N} 1}{\mathrm{~N} 2} \times 100 \%
$$

where $\mathrm{N}_{1}$ is the polypeptide content in the supernatant, g/g; and $\mathrm{N}_{2}$ is the total polypeptide content in the sample, $\mathrm{g} / \mathrm{g}$.

\section{Determination of Emulsibility and Emulsifying Stability}

Emulsibility was measured as described by Vioque et al. (13) with slight modifications. In $40 \mathrm{~mL}$ of distilled water, $2 \mathrm{~g}$ of SCSP, SCSP-I, SCSP-II, or SCSP-III freeze-dried powder was dissolved, and its $\mathrm{pH}$ was adjusted to 7.0 , followed by adding $10 \mathrm{~mL}$ of soybean oil. The sample was homogenized in a high-speed homogenizer (FJ3000, Shanghai Specimen and Model Factory, China) for $2 \mathrm{~min}$, the homogenized mixture was centrifuged at 


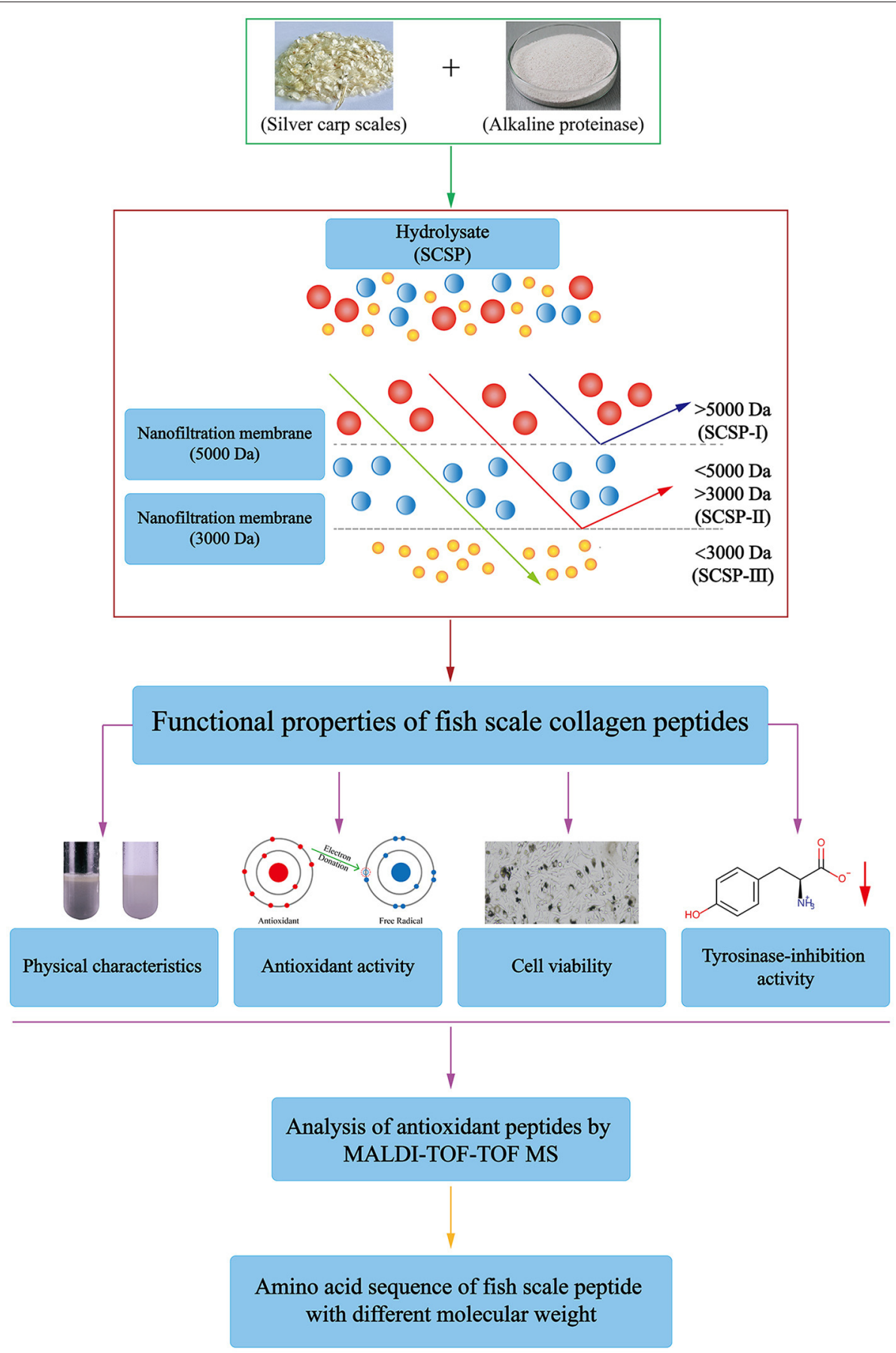

FIGURE 1 | Technical roadmap for the preparation and analysis of SCSPS.

$1,000 \mathrm{rpm}$ for $5 \mathrm{~min}$, and the emulsifying activity index (EAI) was calculated according to Equation (2). After the measurement, the centrifuge tube was placed in a constant-temperature water bath (HH-6, Changzhou Zhiborui Instruments Manufacturing Co., Ltd., China) at $50^{\circ} \mathrm{C}$ for $30 \mathrm{~min}$. After cooling to room temperature, the sample was centrifuged at 1,500 rpm for $10 \mathrm{~min}$. According to Equation (3), the emulsifying stability index (ESI) was calculated.

$$
\begin{aligned}
& \mathrm{EAI}(\%)=\frac{\mathrm{H} 1}{\mathrm{H}} \times 100 \% \\
& \operatorname{ESI}(\%)=\frac{\mathrm{H} 2}{\mathrm{H} 1} \times 100 \%
\end{aligned}
$$


where $\mathrm{H}$ is the total height of the liquid in the centrifuge tube, $\mathrm{cm}$; $\mathrm{H}_{1}$ is the height of the emulsion layer, $\mathrm{cm}$; and $\mathrm{H}_{2}$ is the height of the emulsion layer after centrifugation, $\mathrm{cm}$.

\section{Measurement of Antioxidant Activity}

The freeze-dried powders of SCSP, SCSP-I, SCSP-II, and SCSPIII were added to deionized water to prepare sample solutions of $1,2,4,6,8$, and $10 \mathrm{mg} / \mathrm{mL}$ for the measurement of antioxidant activity.

\section{Measurement of DPPH॰ Scavenging Activity}

The method of Bougatef et al. (14) with slight modifications was used to measure DPPH• scavenging activity. In a test tube, $2.5 \mathrm{~mL}$ of SCSP, SCSP-I, SCSP-II, or SCSP-III sample solution of different concentrations was added, followed by adding $2.5 \mathrm{~mL}$ of DPPH solution $(0.1 \mathrm{mmol} / \mathrm{L})$ prepared in absolute ethanol. The mixture was shaken for $10 \mathrm{~s}$ and then left to react in the dark at room temperature for $30 \mathrm{~min}$. Next, the absorbance of the solution was measured at $517 \mathrm{~nm}$ with an ultravioletvisible spectrophotometer (UH5300, Hitachi High-Technologies Corporation, Japan). The blank control had $2.5 \mathrm{~mL}$ of distilled water. The DPPH radical scavenging rate of the sample solution was calculated according to Equation (4):

$$
\mathrm{DPPH} \text { radical scavenging activity }(\%)=\frac{\mathrm{A} 0-\mathrm{A}}{\mathrm{A} 0} \times 100 \%
$$

where $\mathrm{A}_{0}$ represents the absorbance of the DPPH $\bullet$ ethanol solution without sample and A represents the absorbance of the DPPH• ethanol solution in the measured sample.

\section{Measurement of $\bullet \mathrm{OH}$ Scavenging Activity}

The method of Fu et al. (15) was used to determine the capability of SCSP to scavenge $\bullet \mathrm{OH}$. In an Erlenmeyer flask, $1 \mathrm{~mL}$ of SCSP, SCSP-I, SCSP-II, or SCSP-III sample solution of different concentrations was added with a pipette, followed by adding $1 \mathrm{~mL}$ salicylic acid-ethanol solution $(10 \mathrm{mmol} / \mathrm{L}), 1 \mathrm{~mL} \mathrm{FeSO}$ solution ( $10 \mathrm{mmol} / \mathrm{L}), 2 \mathrm{~mL} \mathrm{H}_{2} \mathrm{O}$, and $5 \mathrm{~mL} \mathrm{H}_{2} \mathrm{O}_{2}$ solution (10 $\mathrm{mmol} / \mathrm{L}$ ). The flask stood at $37^{\circ} \mathrm{C}$ for $15 \mathrm{~min}$. The absorbance of the solution was measured at $510 \mathrm{~nm}$ with an ultraviolet-visible spectrophotometer. The hydroxyl radical scavenging rate of the sample solution was calculated according to Equation (5):

$$
\mathrm{OH} \text { radical scavenging activity }(\%)=\frac{\mathrm{A} 0-\mathrm{A}}{\mathrm{A} 0} \times 100 \%
$$

where $\mathrm{A}_{0}$ represents the background absorbance and $\mathrm{A}$ represents the absorbance of the measured sample.

\section{Measurement of Ferric-Reducing/Antioxidant Power}

The method of Bougatef et al. (14) was used to measure the capability of the SCSP to reduce $\mathrm{Fe}^{3+}$. After $1 \mathrm{~mL}$ of SCSP, SCSP-I, SCSP-II, or SCSP-III sample solution of different concentrations was mixed evenly with $1 \mathrm{~mL}(1 \%) \mathrm{K}_{3}\left[\mathrm{Fe}(\mathrm{CN})_{6}\right]$ and $1 \mathrm{~mL}(0.2 \mathrm{~mol} / \mathrm{L})$ phosphate-buffered saline (PBS) buffer solution, the mixture was reacted in a constant-temperature water bath at $50^{\circ} \mathrm{C}$ for $20 \mathrm{~min}$. After it had cooled to room temperature, $1 \mathrm{~mL}(10 \%)$ trichloroacetic acid solution was added to consume excess $\mathrm{K}_{3}\left[\mathrm{Fe}(\mathrm{CN})_{6}\right]$, and the sample was centrifuged at $4,000 \mathrm{rpm}$ for $10 \mathrm{~min}$. To $2.5 \mathrm{~mL}$ of the supernatant, $0.75 \mathrm{~mL}$ (0.1\%) $\mathrm{FeCl}_{3}$ solution and $2.5 \mathrm{~mL}$ of distilled water were added, the mixture was placed in a constant-temperature water bath at $50^{\circ} \mathrm{C}$ for $10 \mathrm{~min}$ until Prussian blue appears. Then the absorbance of the solution was measured at $700 \mathrm{~nm}$.

\section{Measurement of $\mathrm{O}_{2}^{-}$Radical Scavenging Activity}

The method of Wang et al. (16) with slight modifications was used to determine the $\mathrm{O}_{2}^{-} \bullet$ scavenging activity. In an Erlenmeyer flask, $4.2 \mathrm{~mL}$ of different concentrations of SCSP, SCSP-I, SCSPII, or SCSP-III sample solution was added by pipette, followed by adding $4.5 \mathrm{~mL}$ of Tris- $\mathrm{HCl}(0.1 \mathrm{~mol} / \mathrm{L}, \mathrm{pH} 8.2)$ buffer solution. The sample was mixed evenly and let stand in water bath at $25^{\circ} \mathrm{C}$ for $15 \mathrm{~min}$, followed by quickly adding $0.3 \mathrm{~mL}(3 \mathrm{mmol} / \mathrm{L})$ of pyrogallol (prepared with $10 \mathrm{mmol} / \mathrm{L} \mathrm{HCl}$ ). Then, the solution was mixed evenly. Distilled water instead of peptide solution served as the blank control. The absorbance was measured at $325 \mathrm{~nm}$ every $30 \mathrm{~s}$ for $4 \mathrm{~min}$. The slope of absorbance over time was calculated. The $\mathrm{O}_{2}^{-} \bullet$ scavenging rate of the solution was calculated according to Equation (6):

$$
\begin{aligned}
& \text { Superoxide anion radical scavenging activity (\%) } \\
& =\frac{\mathrm{k} 0-\mathrm{k}}{\mathrm{k}} \times 100 \%
\end{aligned}
$$

where $\mathrm{k}_{0}$ represents the slope of the blank group and $\mathrm{k}$ represents the slope of the sample group.

\section{Cell Viability Determination by MTT Assay and Cell Morphology Observation}

The method of Huang et al. was used to measure cell viability (17). After the B16 melanoma cells in the logarithmic growth phase were inoculated in 96-well plates at $1 \times 10^{4}$ cells/well, they were cultured in an incubator (MCO-15AC, SANYO Electric Co., Ltd., Japan) with $5 \% \mathrm{CO}_{2}$ at $37^{\circ} \mathrm{C}$ for $12 \mathrm{~h}$, and then the medium was changed. Among them, $100 \mu \mathrm{L}$ of sample (0.01, 0.1, 0.5, or $1.0 \mathrm{mg} / \mathrm{mL}$ ) was added to the medium of the experimental group. The positive control group received an equal volume of $\alpha$-arbutin at the same concentration, the blank group an equal volume of medium. After cultivation for $48 \mathrm{~h}, 20 \mu \mathrm{L}$ of $0.5 \% \mathrm{MTT}$ was added to each well, and the cultivation continued for 2 more h. The supernatant was collected, followed by adding $200 \mu \mathrm{L}$ of dimethyl sulfoxide, and the mixture was shaken for $10 \mathrm{~min}$. The absorbance at $490 \mathrm{~nm}$ was measured with a microplate reader (Fluoroskan, Thermo Fisher Scientific Co., Ltd., UK). The cell viability was calculated by Equation (7):

$$
\text { Cell viability }(\%)=\frac{\mathrm{A}}{\mathrm{A} 0} \times 100 \%
$$

where $\mathrm{A}$ is the measured absorbance of the positive control group or the experimental group and $A_{0}$ is the absorbance of the blank group.

To observe the cell morphology, B16 melanoma cells in the logarithmic growth phase were cultured in a cell culture dish. After $12 \mathrm{~h}$, the medium was changed, and $1.0 \mathrm{mg} / \mathrm{mL} \alpha$-arbutin, SCSP, SCSP-I, SCSP-II, or SCSP-III sample solution was added. 
A

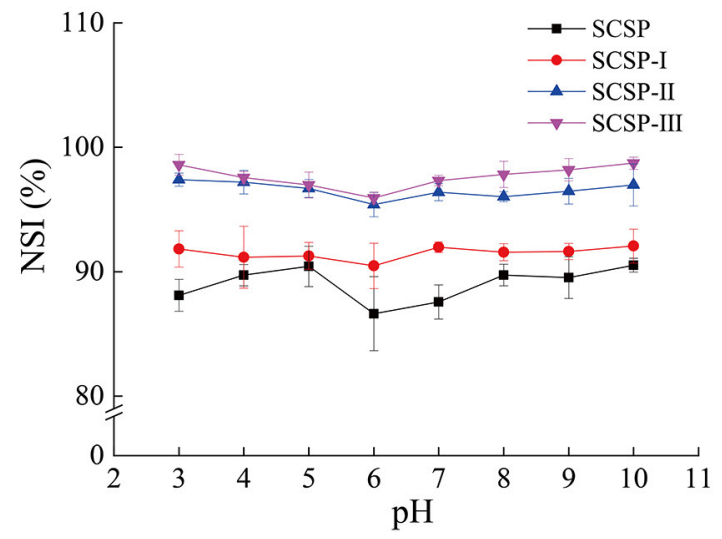

B

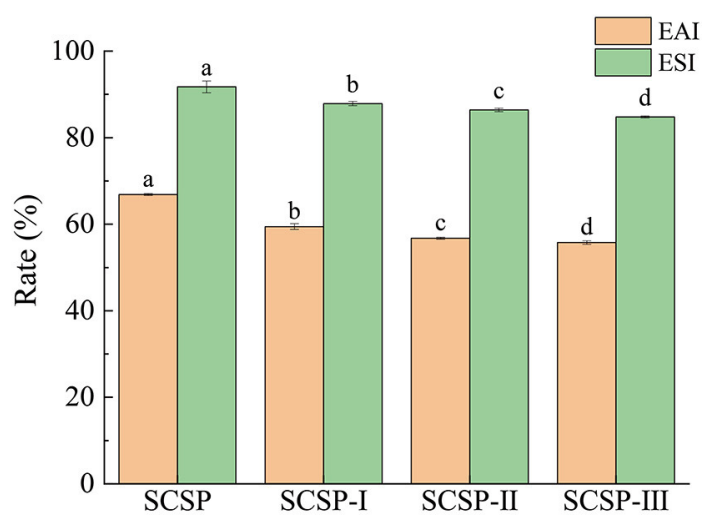

FIGURE 2 | Solubility (A), emulsibility and emulsifying stability (B) of SCSPs. The $0.1 \mathrm{mg} / \mathrm{mL}$ and $50 \mathrm{mg} / \mathrm{mL}$ SCSPs were used in the tests of solubility and emulsibility, respectively. Different lowercase letters denote significant differences between SCSP, SCSP-I, SCSP-II, and SCSP-III groups (P < 0.05). All experiments were repeated three times. Data are expressed as mean \pm standard deviation.

The cultivation continued for 48 more $\mathrm{h}$, and then an inverted microscope (IX7, Olympus Co., Ltd., Japan) was used to observe and photograph the morphology of each group of cells.

\section{Determination of Tyrosinase Activity}

The method of Huang et al. (17) was used to determine the tyrosinase activity. The cell inoculation method, inoculation density, and sample loading method were the same as those of section 2.7. After the cells had been cultured for $48 \mathrm{~h}$, the cells were disrupted with $90 \mu \mathrm{L}$ of PBS ( $\mathrm{pH}$ 6.8) buffer containing $1 \%$ Triton $\mathrm{X}-100$, and the resulting sample was centrifuged at $1,000 \mathrm{rpm}$ for $30 \mathrm{~min}$ in a centrifuge. Considering the toxicity of high concentration $\alpha$-arbutin, low concentration SCSPs of 0.01 $\mathrm{mg} / \mathrm{ml}$ were selected for tyrosinase activity inhibition test. To $90 \mu \mathrm{L}$ of cell disruption solution, $10 \mu \mathrm{L}$ of $1 \mathrm{mg} / \mathrm{mL} \mathrm{L}-3,4-$ dihydroxyphenylalanine (L-DOPA) was added, and the sample was cultured at $37^{\circ} \mathrm{C}$ for $90 \mathrm{~min}$. The absorbance at $475 \mathrm{~nm}$ was measured with a microplate reader. The intracellular tyrosinase activity was calculated by Equation (8):

$$
\text { Tyrosinase activity }(\%)=\frac{\mathrm{A}}{\mathrm{A} 0} \times 100 \%
$$

where $\mathrm{A}$ is the measured absorbance of the positive control group or the experimental group and $\mathrm{A}_{0}$ is the absorbance of the blank group.

\section{Determination of Molecular Weight}

Matrix-assisted laser desorption ionization time-of-flight mass spectrometry (MALDI-TOF-MS) (autoflexmaX, Bruker Co., Ltd., Germany) was used to analyze the molecular weight and molecular weight distribution range corresponding to each SCSP, SCSP-I, SCSP-II, or SCSP-III sample. The sample was mixed with 2,5 -dihydroxybenzoic acid $(20 \mathrm{mg} / \mathrm{mL})$ in $50 \%$ acetonitrile/water (containing $0.1 \%$ trifluoroacetic acid) at a ratio of $1: 1$. After 1 $\mu \mathrm{L}$ of the sample mixture was placed in one well of a 384-well plate and naturally dried at room temperature, the sample plate was placed in the ion source for measurement. The final mass spectrum was obtained by accumulating 10 single-scan signals.

\section{Determination of Amino Acid Sequence}

The amino acid sequence of the peptides was determined by ultraperformance liquid chromatography-tandem mass spectrometry (UPLC-MS/MS) (Agilent6545Q-TOF, Waldbronn, Germany). The sequencing conditions were as follows: the sample volume was $5 \mu \mathrm{L}$, mobile phase A was $0.1 \%$ formic acidacetonitrile, and mobile phase $\mathrm{B}$ was $0.1 \%$ formic acid-water. The gradient elution program was: $1-30 \%$ A (0-45 min), 30-90\% A (45-50 $\mathrm{min}), 90 \% \mathrm{~A}$ (50-52 $\mathrm{min}), 90-1 \% \mathrm{~A}$ (52-55 $\mathrm{min})$, and $1 \%$ A (55-60 min); the flow rate was $0.2 \mathrm{~mL} / \mathrm{min}$. Mass spectrometry conditions: the electrospray ion source was set to electrospray ionization positive ion scanning mode, the nebulizer and drying gas were high-purity nitrogen, the drying temperature was $200^{\circ} \mathrm{C}$, the drying gas flow rate was $6.0 \mathrm{~L} / \mathrm{min}$. And the scanning range was controlled with the MS program with a mass-to-charge ratio $(\mathrm{m} / \mathrm{z})$ of $50-3000$ and the $\mathrm{MS} / \mathrm{MS}$ program with $\mathrm{m} / \mathrm{z}=$ 50-2000. The data were analyzed using the Proteome Discoverer 2.4 software from Thermo Fisher (Thermo Fisher Scientific Co., Ltd., UK), and collagen peptides were classified by searching against the UniProt protein database (www.UniProt.org).

\section{Data Analysis}

IBM SPSS Statistics 20.0 (International Business Machines Corporation Co., Ltd., USA) was used for statistical analysis. Differences with $P<0.05$ were considered statistically significant. Origin 9.1 software (Origin Lab Co., Ltd., USA) was used to draw graphs. All experiments were carried out in triplicate, and the data are expressed as mean \pm standard deviation. 
A

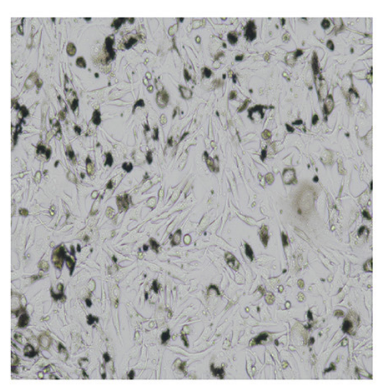

D

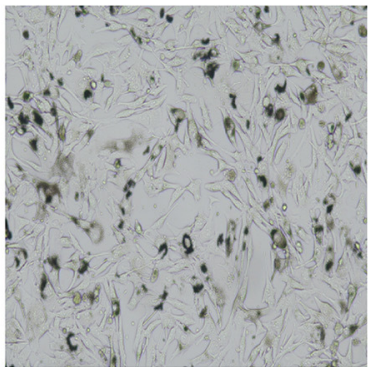

B

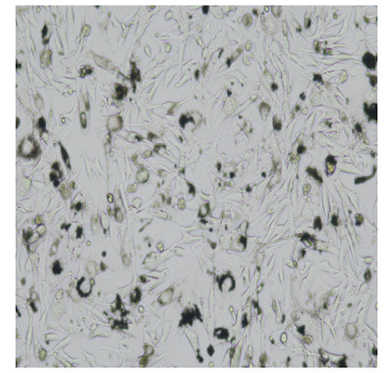

E

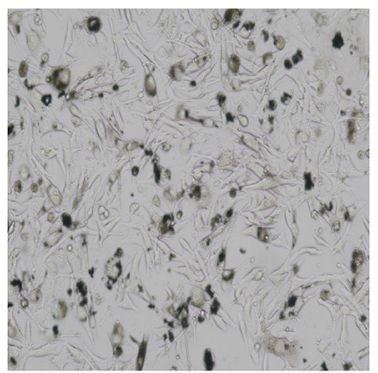

C

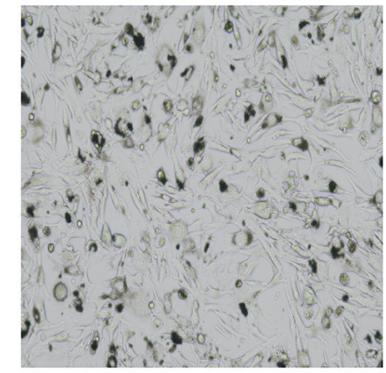

F

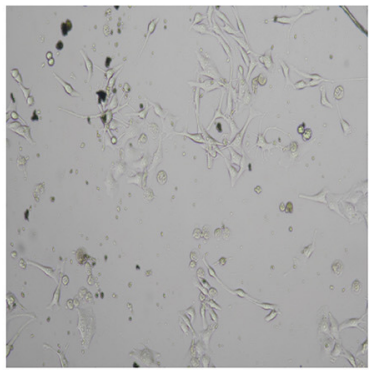

G

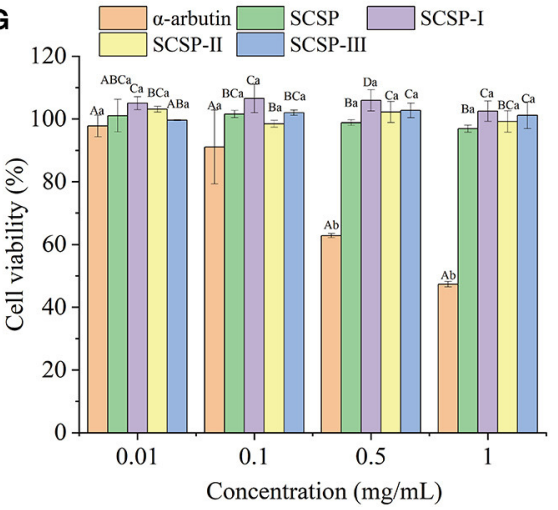

H

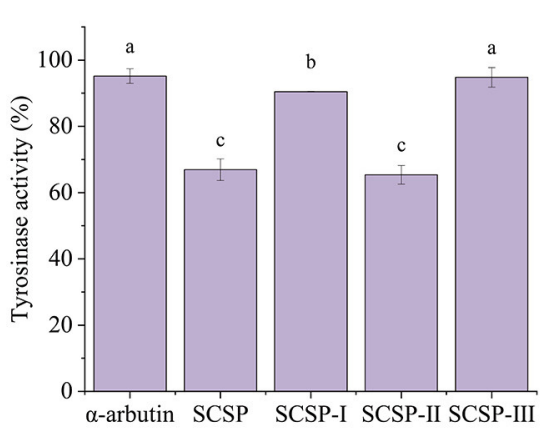

FIGURE 3 | Morphology of mouse B16 melanoma cells in the normal state (blank control) (A), and under the action of $1.0 \mathrm{mg} / \mathrm{mL}$ SCSP (B), SCSP-I (C), SCSP-II (D) SCSP-III (E), and $\alpha$-arbutin (F). The proliferative activity (G) of mouse B16 melanoma cells under the action of SCSPs at 0.01, 0.1, 0.5, 1.0 mg/mL, respectively. The cell tyrosinase activity $\mathbf{( H )}$ under the action of $0.01 \mathrm{mg} / \mathrm{mL}$ SCSPs. In (G), different capital letters denote significant differences between the SCSP, SCSP-I, SCSP-II, and SCSP-III groups at the same concentration $(P<0.05)$, and different lowercase letters denote significant differences between the same fractions of different concentrations $(P<0.05)$. In $(\mathbf{H})$, different lowercase letters denote significant differences between groups $(P<0.05)$. All experiments were repeated three times. Data are expressed as mean \pm standard deviation.

\section{RESULTS}

\section{Solubility, Emulsibility, and Emulsifying Stability of SCSPs}

As shown in Figure 2A, at different $\mathrm{pH}$ values, the solubilities of SCSP and its three fractions were ranked as SCSP-III > SCSP-II > SCSP-I > SCSP. The solubility of each fraction was higher than 90\%, SCSP-III and SCSP-II having solubilities higher than 95\%. In addition, under different $\mathrm{pH}$ values, each fraction showed a similar trend of changes in solubility. When the $\mathrm{pH}$ was $<6$, the solubility of each fraction decreased with increasing $\mathrm{pH}$; when the $\mathrm{pH}$ was $>6$, the solubility of each fraction slowly increased with increasing $\mathrm{pH}$ and eventually plateaued.
As shown in Figure 2B, the emulsibility and emulsifying stability significantly decreased with decreasing molecular weight $(P<0.05)$, emulsibility decreasing more significant than emulsifying stability. The emulsibility of SCSP was $66.89 \pm$ $0.23 \%$, and the emulsifying stability was as high as $91.74 \pm 1.36 \%$ after the sample had stood for $30 \mathrm{~min}$. The emulsibility and emulsifying stability of SCSP-III were only $55.77 \pm 0.40 \%$ and $84.82 \pm 0.23 \%$, respectively.

\section{Antioxidant Effects of SCSPs}

As shown in Figure 3A, in the range of $1-10 \mathrm{mg} / \mathrm{mL}$, the DPPH• scavenging rates of the SCSP and its three fractions all increased with increasing peptide concentration, and the increase in SCSPI group was the most significant $(P<0.05)$. The $\mathrm{O}_{2}^{-} \bullet$ and $\bullet \mathrm{OH}$ 
A

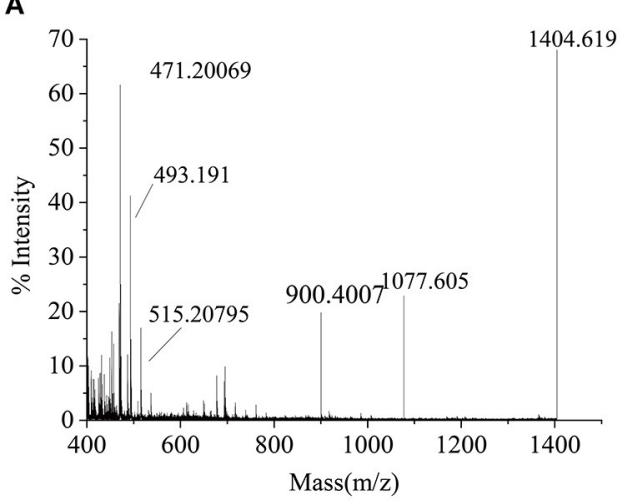

C

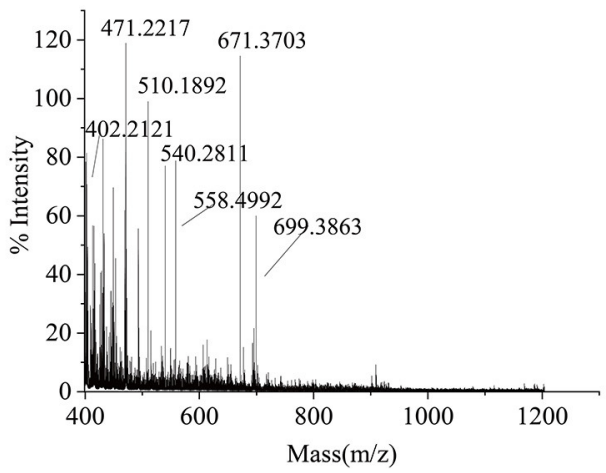

B

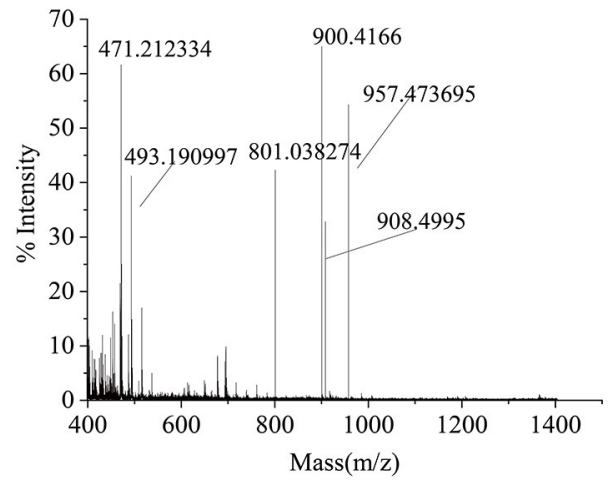

D

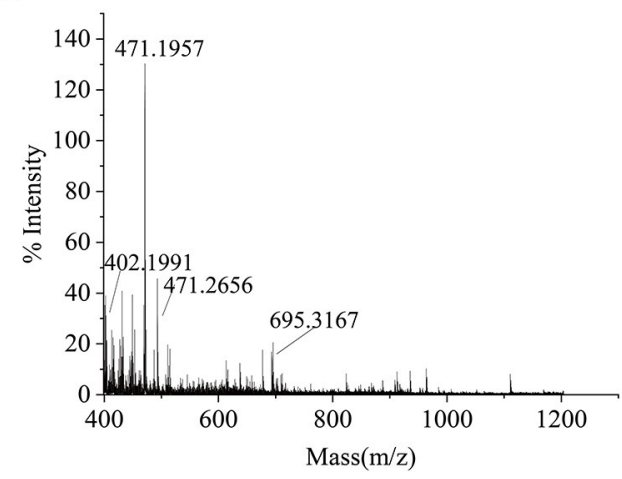

FIGURE 4 | Antioxidant capability of SCSPs. (A) DPPH• radical scavenging capability, (B) hydroxyl radical scavenging capability, (C) ferric-reducing/antioxidant power, (D) superoxide anion radical scavenging capability were measured under the action of SCSPs at 1, 2, 4, 6, 8, 10 mg/mL, respectively. Different capital letters denote significant differences between the SCSP, SCSP-I, SCSP-II, and SCSP-III groups at the same concentration ( $P<0.05)$, and different lowercase letters denote significant differences between the same fractions with different concentrations $(P<0.05)$. All experiments were repeated three times. Data are expressed as mean \pm standard deviation.

scavenging rates and the ferric-reducing/antioxidant power of each fraction showed an upward trend with increasing peptide concentration (Figures 3B-D). At the same concentration, the fractions with lower molecular weights had higher antioxidant capability (Figures 3B-D).

\section{Effects of SCSPs on the Proliferation of Mouse B16melanoma Cells}

Figures 4A-F shows the morphology of mouse B16 melanoma cells under the action of $1.0 \mathrm{mg} / \mathrm{mL}$ sample. The cells in each SCSP group displayed uniform adhesion and were mostly spindle-shaped, with normal morphology, clear cell edges, and high cell density (Figures 4B-E). The SCSP groups were not significantly different from the blank control group (Figure 4A). In the $\alpha$-arbutin group (Figure $4 \mathbf{F}$ ), there were many apoptotic cells and no complete cell structure, the intercellular spaces became larger, dendritic structures disappeared, and there were fewer cells. The cell morphology results supported the results of the MTT cell viability assay. As shown in Figure 4G, except for $\alpha$-arbutin, each sample had similar effects on the proliferation of mouse B16 melanoma cells as its concentration changed $(P$ $>0.05)$. There was no significant difference in the proliferation of mouse B16 cells when the $\alpha$-arbutin concentration was in the range of $0.01-0.1 \mathrm{mg} / \mathrm{mL}(P>0.05)$. But when the $\alpha-$ arbutin concentration was higher than $0.1 \mathrm{mg} / \mathrm{mL}$, it significantly inhibited B16 cell proliferation $(P<0.05)$, such that the cell survival rate was only $47.34 \pm 0.88 \%$ in $1.0 \mathrm{mg} / \mathrm{mL} \alpha$-arbutin.

\section{Effects of SCSPs on the Tyrosinase Activity}

Under the condition of $0.01 \mathrm{mg} / \mathrm{mL}$, the effect of SCSPs on tyrosinase activity was studied with $\alpha$-arbutin as positive control. As shown in Figure $\mathbf{4 H}$, the inhibitory effect of each fraction on tyrosinase was higher than that of $\alpha$-arbutin. Among them, the tyrosinase activity of the SCSP-II group was $65.37 \pm 2.81 \%$, which was significantly lower than that of the arbutin group $(P<0.05)$. Moreover, SCSP-II was seems to be safer to cells than $\alpha$-arbutin. Tyrosinase is a key enzyme in the synthesis of melanin.

\section{Molecular Weight Ranges of SCSPs}

As seen in Figure 5A, the molecular weight distribution of peptides in the SCSP ranged from 399 to $1404 \mathrm{Da}$, of which m/z 471.20 and 1404.62 were relatively abundant. Figure 5B shows that the molecular weight of SCSP-I ranged from 399 to 957 $\mathrm{Da}$, of which $\mathrm{m} / \mathrm{z} 471.21$, and 900.42 were relatively abundant. Figure 5C shows that the molecular weight of SCSP-II ranged 

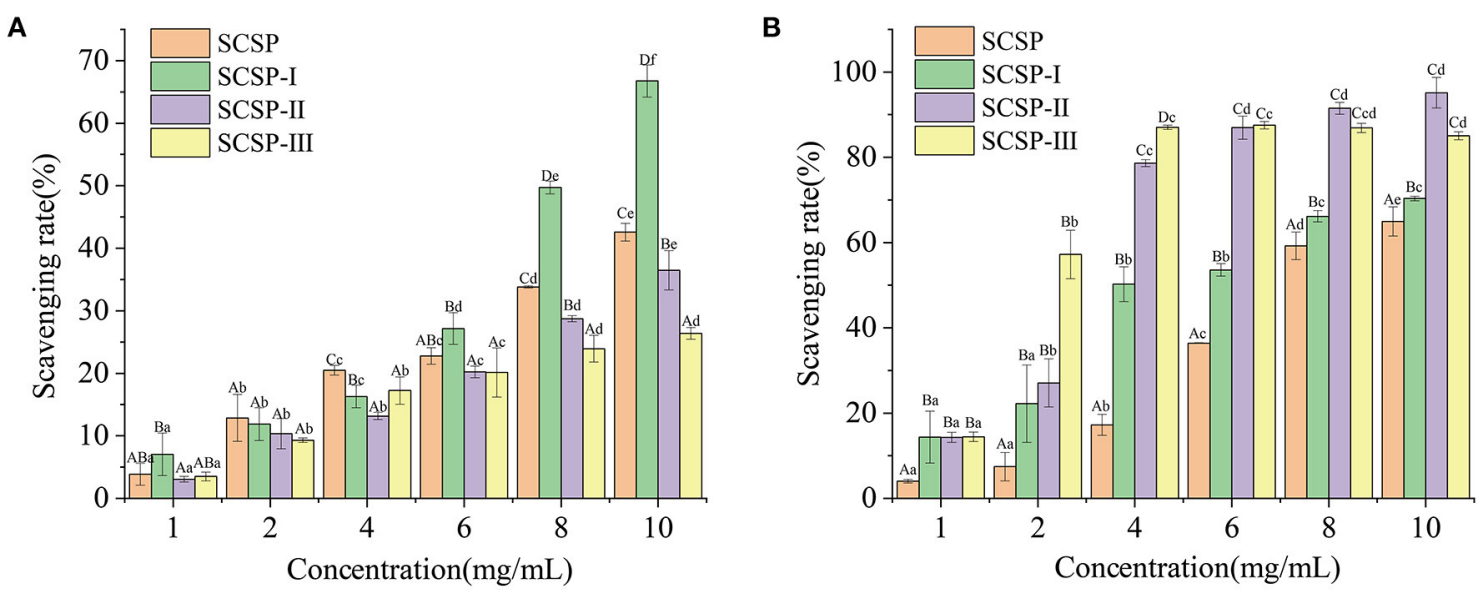

C

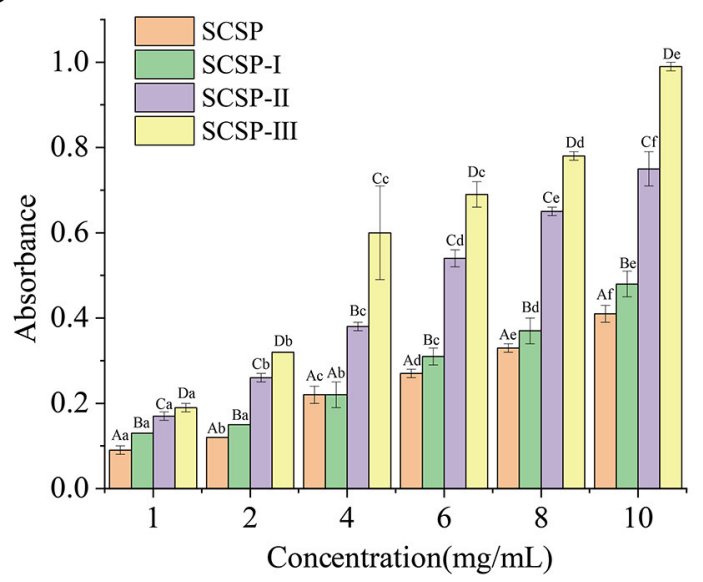

D

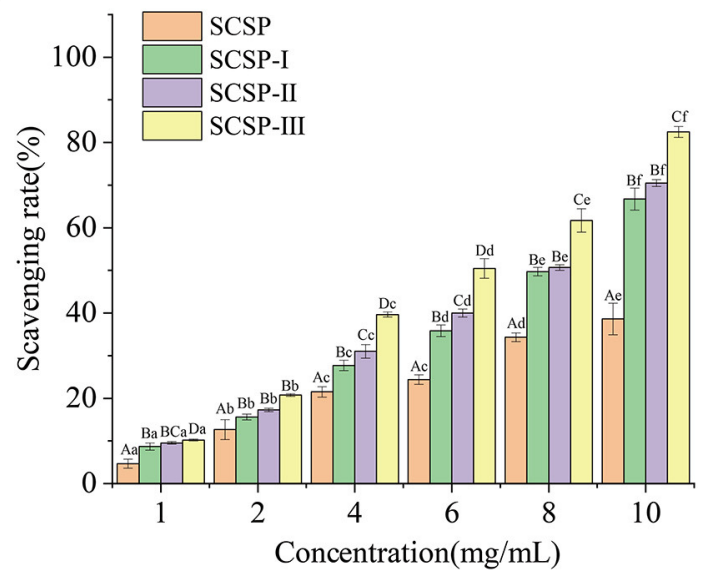

FIGURE 5 | MALDI-TOF-MS spectral profiles of SCSPS. (A) SCSP, (B) SCSP-I, (C) SCSP-II, (D) SCSP-III.

TABLE 1 | The peptide sequence and molecular weight of SCSPS.

\begin{tabular}{|c|c|c|c|c|c|}
\hline No. & Sequence & Theo. $\mathrm{MH}+[\mathrm{Da}]$ & NF component & Confidence & XCor \\
\hline a & GARGDKGETGEA & 1,147 & SCSP-I & High & 3.30 \\
\hline b & SGPAGPRGPAGSSGPA & 1,322 & SCSP-I & High & 3.24 \\
\hline$d$ & GERGEQGPA & 900 & SCSP-I & High & 1.90 \\
\hline e & AGDPGPV & 612 & SCSP-II & High & 1.86 \\
\hline h & GRVGPA & 556 & SCSP-II & High & 1.59 \\
\hline i & GAQGPIGA & 670 & SCSP-II & High & 1.50 \\
\hline j & GNPGPA & 512 & SCSP-II & High & 1.23 \\
\hline k & GPAGPA & 469 & SCSP-III & High & 2.15 \\
\hline । & GPSGPA & 485 & SCSP-III & High & 1.73 \\
\hline
\end{tabular}

The amino acids represented by capital letters in the table are as follows: A-Ala, G-Gly, R-Arg, D-Asp, K-Lys, E-Glu, S-Ser, M-Met, P-Pro, Q-Gln, V-Val, and I-lle.

from 399 to $699 \mathrm{Da}$, of which $\mathrm{m} / \mathrm{z} 471.22$ and 671.37 were relatively abundant. Figure 5D shows that the molecular weight of SCSP-III ranged from 399 to $695 \mathrm{Da}$, in which $\mathrm{m} / \mathrm{z} 471.20$ were relatively abundant. The above results indicate that silver carp scales underwent complete enzymolysis under the action of alkaline protease. 


\section{Amino Acid Sequence of SCSPs}

As shown in Table 1, a total of 13 peptides were identified in SCSP. The peptides contained many Gly, Ala, and Pro, and Gly accounted for approximately $33.30 \%$ of the total sequence. These types of amino acids are essential amino acids for the synthesis of collagen (18). According to the molecular weight ranges of the peptides in Table 1, Figure 5, the obtained peptides were classified into the fractions SCSP-I, SCSP-II, and SCSP-III. The content of hydrophobic amino acids in the peptides GPAGPA, GPSGPA, and GIAGPA was generally higher than those of other peptides. Correspondingly, the antioxidant activity of SCSP-III was also higher than those of other SCSPs.

\section{DISCUSSION}

\section{Physical Properties of SCSPs}

According to the test results, the smaller the molecular weight of the peptide is, the higher the solubility is. The balance of hydrophilic forces and hydrophobic forces is a key factor affecting the solubility of peptides. Peptides with smaller molecular weights are expected to obtain more polar residues $-\mathrm{COOH}$, -NH2, -OH, etc. (19). These hydrophilic groups can form hydrogen bonds with $\mathrm{H} 2 \mathrm{O}$ and increase the force between peptide molecules and solvent molecules, thereby increasing the solubility of the peptide. With the increase of $\mathrm{pH}$ value, the solubility of the same SCSP first decreases and then increases and there seems to be a turning point at $\mathrm{pH} 6$ (Figure 2A). This is because the solubility of the peptide also depends on the net charge of the molecule. The peptide solution near the isoelectric point is neutral, and the interaction between the solute and the solvent is stronger than the electrostatic effect, leading to aggregation and precipitation between the peptide solute molecules and a reduction of the solubility (20). When the $\mathrm{pH}$ is away from the isoelectric point, under the combined action of intermolecular force and electrostatic force, the peptide solute can be effectively dispersed in the solvent system, and the solubility increases. In the experiment, the emulsibility and emulsifying stability decreased with decreasing molecular weight (Figure 2B). This may be because the low intermolecular crosslinking of low-molecular-weight peptides is not enough to form a stable dispersion system, resulting in the decreases in emulsibility and emulsifying stability (21).

\section{Antioxidant Effects of SCSPs}

On the case of DPPH results, there seems to be little correlations between DPPH clearance and peptide molecular weight, because that small-molecule peptides are mostly more polar and hydrophilic, making them less reactive with lipophilic DPPH• free radicals (22). This difference may also have been related to the highest histidine mass fraction (0.14\%) in SCSP-I. Because histidine is an important active site of antioxidant peptides, it can act as a proton donor to combine with DPPH•, thus improving the efficiency of SCSP-I at free radical scavenging (23). Figures 3B-D shows that the antioxidant powers were ranked as SCSP-III > SCSP-II > SCSP-I > SCSP, which was different from the ordering of DPPH• scavenging rates. This may be because the polar molecules of low-molecular-weight peptides can provide many electrons, which can convert free radicals into stable products and terminate free-radical chain reactions $(23,24)$. Therefore, small-molecule peptides may exhibit better antioxidant properties in this respect.

\section{Biological Activities of SCSPs}

An increase in melanin can lead to hyperpigmentation disorders, forming dark spots, spots, and freckles (25). Therefore, tyrosinase inhibitors, as an effective component to promote skin whitening, have received extensive attention in the field of cosmetics (26). Choi et al. have shown that low concentrations of fish scale peptide can be absorbed by cells and can effectively inhibit the tyrosinase activity in melanoma cells (27), which is supported by the results of this work. The $\alpha$-arbutin produces toxic and side effects at high concentrations, blocking cell activity and causing cell apoptosis (28). In contrast, the fractions of SCSP were highly safe to mouse B16 cells even at high concentrations.

\section{Relations Between SCSP Biological Activity and Amino Acid Sequence}

After enzymolysis, the resulting products were mostly smallmolecule substances, and the signal intensity of small-molecule peptides after nanofiltration was significantly higher than that before nanofiltration, in line with the results of Cinq-Mars et al. (29). The primary structure and molecular weight of a peptide directly determines the strength of its antioxidant activity (21, 30).

In the work, the sequences of the SCSP-II and SCSPIII fractions were both shorter than 10 amino acids (Table 1), and compared with SCSP-I, the two had stronger antioxidant capability. These results are consistent with Ma's conclusion that short peptides have greater antioxidant activities (6). The content of hydrophobic amino acids in SCSP-III was higher than that of other SCSPs. This may be because hydrophobic amino acids act as hydrogen donors to interact with other amino acids to enhance the hydrophobic properties of the polypeptides (31), or act as hydrogen donors to react with metal ions and free radicals to reduce the oxidation rate (32), thereby enhancing their antioxidant capability.

The Gly, Ala, Ser, and Leu present in the fish scale peptides after nanofiltration can also enhance the peptides' tyrosinase inhibitory activity, thereby inhibiting the production of melanin and giving them a strong whitening effect (33). In addition, the combination of Arg or Phe residues and hydrophobic aliphatic residues (such as Val, Ala or Leu) can directly interact with tyrosinase to inhibit the formation of quinines (34). In RGDVGPA and GRVGPA of SCSPII, Arg is combined with hydrophobic amino acids, which may be why SCSP-II showed strong tyrosinase inhibition (Figure 4H).

\section{CONCLUSIONS}

The solubility of each component of SCSP was higher than $90 \%$, and the smaller the molecular weight, the higher the solubility. In terms of antioxidation, generally, the lower the 
molecular weight of the peptide, the stronger the antioxidative activity. Among them, SCSP-III had a good scavenging effect on $\bullet \mathrm{OH}$ and $\mathrm{O}_{2}^{-} \bullet$ and had a strong ferric reducing/antioxidant power. Cell experiments in vitro showed that at a concentration of $0.01 \mathrm{mg} / \mathrm{mL}$, SCSP-II had the strong inhibitory effect on tyrosinase, which was significantly better than that of $\alpha$-arbutin. This peptide fraction was safe, exhibiting no toxic or side effects. The molecular weight distribution of SCSP was $399.83 \sim$ 1404.62 Da by MALDI-TOF-MS, and 13 peptide sequences were detected by UPLC-MS/MS. The peptides GPAGPA, GPSGPA, and GIAGPA, with relatively high contents of hydrophobic amino acids, may underlie the strong antioxidant activity of SCSP-III. The combination of Arg and hydrophobic amino acids in RGDVGPA and GRVGPA may be the reason why the SCSP-II component strongly inhibits tyrosinase. The above results indicate that short peptides SCSP-II and SCSP-III have good biological activity and can replace $\alpha$-arbutin for melanin inhibition and oxidation inhibition. At present, although the SCSP shows the possibility of replacing $\alpha$-arbutin as a whitening agent, but the product forms and sensory qualities (such as color, taste and smell) need to be further studied before application.

\section{REFERENCES}

1. Faralizadeh S, Rahimabadi EZ, Bahrami SH, Hasannia S. Extraction, characterization and biocompatibility evaluation of silver carp (Hypophthalmichthys molitrix) skin collagen. Sustain Chem Pharm. (2021) 22:100454. doi: 10.1016/j.scp.2021.100454

2. Liu D, Nikoo M, Boran G, Zhou P, Regenstein JM. Collagen and gelatin. Annu Rev Food Sci Technol. (2015) 6:52757. doi: 10.1146/annurev-food-031414-111800

3. Nagai T, Izumi M, Ishii M. Fish scale collagen. preparation and partial characterization. Int J Food Sci Technol. (2010) 39:239-44. doi: 10.1111/j.1365-2621.2004.00777.x

4. Huang CY, Wu CH, Yang JI, Li YH, Kuo JM. Evaluation of iron-binding activity of collagen peptides prepared from the scales of four cultivated fishes in Taiwan. J Food Drug Anal. (2015) 23:671-8. doi: 10.1016/j.jfda.2014.06.009

5. Kim SK, Kim YT, Byun HG, Nam KS, Joo DS, Shahidi F. Isolation and characterization of antioxidative peptides from gelatin hydrolysate of Alaska pollack skin. J Agric Food Chem. (2001) 49:1984-9. doi: 10.1021/jf000494j

6. Ma Y, Xiong YL, Zhai J, Zhu H, Dziubla T. Fractionation and evaluation of radical-scavenging peptides from in vitro digests of buckwheat protein. Food Chemist. (2010) 118:582-88. doi: 10.1016/j.foodchem.2009.05.024

7. Tang X, He Z, Dai Y, Xiong YL, Xie M, Chen J. Peptide fractionation and free radical scavenging activity of zein hydrolysate. J Agric Food Chem. (2010) 58:587-93. doi: 10.1021/jf9028656

8. Wu X, Cai L, Zhang Y, Mi H, Li J. Compositions and antioxidant properties of protein hydrolysates from the skins of four carp species. Int J Food Sci Technol. (2015) 50:2589-97. doi: 10.1111/ijfs.12927

9. Zhang JY, Deng H, Bai J, Zhou XH, Zhao YS, Zhu Y, et al. Healthpromoting properties of barley: a review of nutrient and nutraceutical composition, functionality, bioprocessing, and health benefits. Crit Rev Food Sci Nutr. (2021).

10. Ogawa M, Portie RJ, Moody MW, Bell J, Schexnayder MA, Losso JN. Biochemical properties of bone and scale collagens isolated from the subtropical fish black drum (Pogonia cromis) and sheepshead seabream (Archosargus probatocephalus). Food Chem. (2004) 88:495-501. doi: 10.1016/j.foodchem.2004.02.006

11. Fisher AA. The safety of bleaching creams containing hydroquinone. Cutis. (1998) 61:303-4.

\section{DATA AVAILABILITY STATEMENT}

The original contributions presented in the study are included in the article/supplementary material, further inquiries can be directed to the corresponding authors.

\section{AUTHOR CONTRIBUTIONS}

XYZ: writing-original draft, formal analysis, methodology, investigation, and funding acquisition. YJZ: data curation, visualization, and writing-review and editing. SMF: visualization and writing-review and editing. TL: investigation and writing-review and editing. HLL: conceptualization, writing-review and editing, project administration, and funding acquisition. GQX: supervision, visualization, and writing-review and editing. All authors contributed to the article and approved the submitted version.

\section{FUNDING}

This work was financed by the National Key Research and Development Program of China (2019YFD0902000).

12. Adler-Nissen J. Enzymic hydrolysis of food proteins. Can Med Assoc J. (1986) 172:1783-5.

13. Vioque J, Sánchez-Vioque R, Clemente A, Pedroche J, Millán F. Partially hydrolyzed rapeseed protein isolates with improved functional properties. $J$ Am Oil Chem Soc. (2000) 77:447-50. doi: 10.1007/s11746-000-0072-y

14. Bougatef A, Nedjar-Arroume N, Manni L, Ravallec R, Barkia A, Guillochon $D$, et al. Purification and identification of novel antioxidant peptides from enzymatic hydrolysates of (Sardinella aurita) by-products proteins. Food Chem. (2010) 118:559-65. doi: 10.1016/j.foodchem.2009.05.021

15. Fu R, Zhang Y, Guo Y, Chen F. Antioxidant and tyrosinase inhibition activities of the ethanol-insoluble fraction of water extract of sapium sebiferum (L) roxb leaves. S Afr J Botany. (2014) 93:98-104. doi: 10.1016/j.sajb.2014.04.003

16. Wang B, Li ZR, Chi CF, Zhang QH, Luo HY. Preparation and evaluation of antioxidant peptides from ethanol-soluble proteins hydrolysate of Sphyrna lewini muscle. Peptides. (2012) 36:240-50. doi: 10.1016/j.peptides.2012.05.013

17. Huang $\mathrm{YC}$, Yang $\mathrm{CH}$, Chiou YL. Citrus flavanone naringenin enhances melanogenesis through the activation of $\mathrm{Wnt} / \beta$-catenin signalling in mouse melanoma cells. Phytomedicine. (2011) 18:1244-9. doi: 10.1016/j.phymed.2011.06.028

18. $\mathrm{Li} \mathrm{P}, \mathrm{Wu} \mathrm{G}$. Roles of dietary glycine, proline, and hydroxyproline in collagen synthesis and animal growth. Amino Acids. (2018) 50:2938. doi: 10.1007/s00726-017-2490-6

19. Gbogouri GA, Linder M, Fanni J, Parmentier M. Influence of hydrolysis degree on the functional properties of salmon byproducts hydrolysates. J Food Sci. (2006) 69:C615-22. doi: 10.1111/j.1365-2621.2004.tb09909.x

20. Jongjareonrak A, Benjakul S, Visessanguan W, Nagai T, Tanaka M. Isolation and characterisation of acid and pepsin-solubilised collagens from the skin of Brownstripe red snapper (Lutjanus vitta). Food Chem. (2006) 93:47584. doi: 10.1016/j.foodchem.2004.10.026

21. Jeon YJ, Byun HG, Kim SK. Improvement of functional properties of cod frame protein hydrolysates using ultrafiltration membranes. Process Biochemist. (1999) 35:471-8. doi: 10.1016/S0032-9592(99)0 0098-9

22. Zhu L, Chen J, Tang X, Xiong YL. Reducing, radical scavenging, and chelation properties of in vitro digests of alcalase-treated zein hydrolysates. J Agric Food Chemist. (2008) 56:3884. doi: 10.1021/jf801328j

23. Wu R, Wu C, Liu D, Yang $\mathrm{X}$, Huang J, Zhang J, et al. Antioxidant and anti-freezing peptides from salmon collagen hydrolysate 
prepared by bacterial extracellular protease. Food Chem. (2018) 248:346-52. doi: 10.1016/j.foodchem.2017.12.035

24. Park SH, Jo YJ. Static hydrothermal processing and fractionation for production of a collagen peptide with anti-oxidative and anti-aging properties. Process Biochemist. (2019) 83:176-82. doi: 10.1016/j.procbio.2019.05.015

25. Phanuwat P, Ninnaj C, Papassara S, Tanatorn S, Aphichart K. Inhibitory activities of protein hydrolysates from spotted Babylon snails on tyrosinase and melanogenesis. J Aquat Food Product Technol. (2018) 27:1-19. doi: 10.1080/10498850.2018.1499687

26. Karkouch I, Tabbene O, Gharbi D, Mlouka MAB, Elkahoui S, Rihouey $\mathrm{C}$, et al. Antioxidant, antityrosinase and antibiofilm activities of synthesized peptides derived from Vicia faba protein hydrolysate: a powerful agents in cosmetic application. Ind Crop Prod. (2017) 109:310-9. doi: 10.1016/j.indcrop.2017.08.025

27. Choi HK, Lim YS, Kim YS, Park SY, Lee CH, Hwang KW, et al. Freeradical-scavenging and tyrosinase-inhibition activities of Cheonggukjang samples fermented for various times. Food Chem. (2008) 106:5648. doi: 10.1016/j.foodchem.2007.06.024

28. Jiang L, Wang D, Zhang Y, Li J, Wu Z, Wang Z, et al. Investigation of the pro-apoptotic effects of arbutin and its acetylated derivative on murine melanoma cells. Int J Mol Med. (2018) 41:1048-54. doi: 10.3892/ijmm.201 7.3256

29. Cinq-Mars $\mathrm{CD}$, Hu $\mathrm{C}$, Kitts $\mathrm{DD}$, Li-Chan ECY. Investigations into inhibitor type and mode, simulated gastrointestinal digestion, and cell transport of the angiotensin I-converting enzymeinhibitory peptides in Pacific hake (Merluccius productus) fillet hydrolysate. J Agric Food Chem. (2008) 56:410-9. doi: 10.1021/jf07 $2277 \mathrm{p}$

30. Suetsuna K, Ukeda H, Ochi H. Isolation and characterization of free radical scavenging activities peptides derived from casein. $J$ Nutr Biochem. (2000) 11:128-31. doi: 10.1016/S0955-2863(99)0 0083-2
31. Chen HM, Muramoto K, Yamauchi F, Nokihara K. Antioxidant activity of designed peptides based on the antioxidative peptide isolated from digests of a soybean protein. J Agric Food Chem. (1996) 44:261923. doi: 10.1021/jf950833m

32. Mendis E, Rajapakse N, Kim SK. Antioxidant properties of a radicalscavenging peptide purified from enzymatically prepared fish skin gelatin hydrolysate. J Agric Food Chem. (2005) 53:581-7. doi: 10.1021/jf048877v

33. Park SY, Lee JO, Baek HE, Lee HG. Purification and characterization of antioxidant peptides from soy protein hydrolysate. J Food Biochem. (2010) 34:120-32. doi: 10.1111/j.1745-4514.2009.00313.x

34. Schurink M, van Berkel WJ, Wichers HJ, Boeriu CG. Novel peptides with tyrosinase inhibitory activity. Peptides. (2007) 28:485-95. doi: 10.1016/j.peptides.2006.11.023

Conflict of Interest: The authors declare that the research was conducted in the absence of any commercial or financial relationships that could be construed as a potential conflict of interest.

Publisher's Note: All claims expressed in this article are solely those of the authors and do not necessarily represent those of their affiliated organizations, or those of the publisher, the editors and the reviewers. Any product that may be evaluated in this article, or claim that may be made by its manufacturer, is not guaranteed or endorsed by the publisher.

Copyright (c) $2022 \mathrm{Zu}$, Zhao, Fu, Liao, Li and Xiong. This is an open-access article distributed under the terms of the Creative Commons Attribution License (CC BY). The use, distribution or reproduction in other forums is permitted, provided the original author(s) and the copyright owner(s) are credited and that the original publication in this journal is cited, in accordance with accepted academic practice. No use, distribution or reproduction is permitted which does not comply with these terms. 